\title{
Novel 12S mtDNA findings in sloths (Pilosa, Folivora) and anteaters (Pilosa, Vermilingua) suggest a true case of long branch attraction
}

\author{
Maria Claudene Barros ${ }^{1}$, Iracilda Sampaio ${ }^{2}$ and Horacio Schneider ${ }^{2}$ \\ ${ }^{1}$ Universidade Estadual do Maranhão, Caxias, MA, Brazil. \\ ${ }^{2}$ Laboratório de Genética e Biologia Molecular, Instituto de Estudos Costeiros, \\ Universidade Federal do Pará, Bragança, PA, Brazil.
}

\begin{abstract}
We sequenced 12S RNA mtDNA for the majority of the extant species of sloths and anteaters and compared our results with previous data obtained by our group using 16S RNA mtDNA in the same specimens and to GenBank sequences of the extinct giant sloth Mylodon. Our results suggest that pigmy-anteaters may be a case of the long-branch attraction phenomenon and also show the large genetic difference between the Amazonian and Atlantic forest three-toed sloths, contrasting with the small differences observed between the two non-Atlantic forest forms of sloths. These results have important implications for the taxonomy of sloths and anteaters and strongly suggest the placement of pigmy anteaters in their own family (Cyclopidae) and raising the taxonomic status of Bradypus torquatus to a genus.
\end{abstract}

Key words: anteaters, molecular evolution, mylodont, sloths, Xenarthra.

Received: May 29, 2007; Accepted: November 13, 2007.

In the past, xenarthrans (armadillos, anteaters and sloths) were one of the most diverse groups in South America with more than 200 known fossil genera (MacKenna and Bell, 1997) but there are now only 13 genera and 30 extant species. Almost all xenarthrans endemic to South and Central America, the exception being the armadillo (Dasypus novemcinctus), which occurs in North America.

Sloths almost became extinct about ten thousand years ago, with only two genera and five species still surviving in Central and South America. MacKenna and Bell (1997) placed sloths into two infraorders consisting of the extinct Mylodon and the Megatheria, the latter being considered as an assemblage of extinct families, the Megatheriidae, and the extant families Bradypodidae, containing the genus Bradypus composed of only three species (B. tridactylus, B. variegatus and B. torquatus), and Megalonychidae, containing the genus Choloepus with only two species (C. didactylus and C. hoffmanni).

The anteaters, the closest partner to the sloths, show great variation in size between genera, ranging from $16 \mathrm{~kg}$ to $23 \mathrm{~kg}$ for the strictly terrestrial giant anteater Myrmecophaga tridactyla, to $3.8 \mathrm{~kg}$ to $8.5 \mathrm{~kg}$ for the medium-sized semi-arboreal anteater Tamandua tetradactyla

Send correspondence to Horacio Schneider. Instituto de Estudos Costeiros, Universidade Federal do Pará, Alameda Leandro Ribeiro Bloco B s/n, 68600-000 Bragança, PA, Brazil. E-mail: horacio@ ufpa.br. and $155 \mathrm{~g}$ to $275 \mathrm{~g}$ for the diminutive arboreal pigmy anteater Cyclopes didactyla, all of which are included in the family Myrmecophagidae.

Despite distinctive morphology and specialization, anteaters and sloths are considered as a monophyletic assemblage, the Pilosa clade, as supported by morphological (Engelmann, 1985; Gaudin, 2004; MacKenna and Bell, 1997; Paterson et al., 1992) and molecular evidence (Delsuc et al., 2001). Delsuc et al. (2004) applied Bayesian analysis to three nuclear genes (5130 sites) and obtained a molecular time scale for the evolution of extant xenarthrans and other mammals indicating that the age of the Pilosa node is around 55 megaannum (Ma, equal to $10^{6}$ years) before the present (BP), with node ages of $40 \mathrm{Ma} \mathrm{BP}$ for anteaters and $21 \mathrm{Ma}$ BP for sloths.

The majority of sloths became extinct about ten thousand years ago, so obtaining an understanding of the phylogenetic relationships between extinct and extant sloths is a great challenge. Gaudin (1995) was one of the first to propose an association between extinct mylodonts and extant megalonichyd sloths based on morphological characteristics. Höss et al.. (1996) proposed that the extinct Pleistocene giant sloth Mylodon is more closely related to the extant Choloepus than to Bradypus based on partial sequences of $12 \mathrm{~S}$ and $16 \mathrm{~S}$ rDNA mitochondrial genes from the extinct Mylodon darwinii and only four extant xenarthrans (the sloths $B$. variegatus and $C$. didactylus, the 
armadillo Cabassous unicinctus and the anteater $T$. tetradactyla). Greenwood et al. (2001) sequenced two fragments of the mitochondrial cytochrome $b$ and $12 \mathrm{~S}$ rDNA genes from the extant sloths Bradypus and Choloepus and the extinct sloths Mylodon darwinii (a mylondontid) and Nothrotheriops shastensis (a megatherid) and produced data supporting the Mylodon-megalonychid and Bradypus-megatherid arrangement suggested by Höss (1996), in spite of the low statistical support obtained for these arrangements. Gaudin (2004) examined 286 osteological characters and proposed that Bradypus and Choloepus do not share a recent common ancestor and that the split between Bradypus and Choloepus is an ancient event dating back perhaps 40 Ma BP. Gaudin (2004) also advocated the placement of the extant three-toed sloth Bradypus as the sister group to all other extant and extinct sloths in a clade named Eutardigrada and, furthermore, suggested combining the extant Choloepus with the extinct members of the family Megalonychidae.

In our previous paper (Barros et al., 2003) 16S mitochondrial DNA sequences from almost all extant sloths was compared with previously published sequences of the extinct Mylodon darwinii but we found no statistical support for a phylogenetic relationship between Mylodon and Megalonychidae. During the work described in the present paper we included additional mtDNA12S sequences in our analysis in the hope of not only clarifying the phylogenetic relationship of Mylodon but also contributing to an understanding of the recent phylogenetic events in this group.

We extracted total DNA from blood or a small piece of ear skin of the sloths B. tridactylus, B. torquatus, $B$. variegatus and Choloepus didactylus as well as the anteaters $C$. didactylus, M. tridactyla and T. tetradactyla. Details about the origin and number of specimens sampled for each species as well as the GenBank accession numbers are listed in Table 1. Only distinct sequences of each species were used for the phylogenetic reconstructions. All animals used were healthy adults and were not harmed by the procedures. Blood or tissues were transported to our laboratory, processed immediately or stored frozen until needed.

For DNA extraction, samples were digested with ribonuclease (Promega, USA) for $1 \mathrm{~h}$ at $37^{\circ} \mathrm{C}$ followed by Proteinase K (Promega, USA) treatment for $2 \mathrm{~h}$ to $4 \mathrm{~h}$ (or overnight) at $55^{\circ} \mathrm{C}$ and the DNA purified by standard phenol/chloroform extraction and precipitation with isopropanol (Sambrook et al., 1989). For each DNA sample, a fragment of about 500 base pairs of mitochondrial $12 \mathrm{~S}$ rRNA was amplified using the primers previously described in Höss et al. (1996). The polymerase chain reaction (PCR) amplifications were performed in $100 \mu \mathrm{L}$ of a reaction mixture containing $16 \mu \mathrm{L}$ of $1.25 \mathrm{mM}$ dNTP, $10 \mu \mathrm{L}$ of buffer (10X conc.), $4 \mu \mathrm{L}$ of $25 \mathrm{mM} \mathrm{MgCl} 2,1 \mu \mathrm{L}$ of each primer $\left(200 \mathrm{ng} \mu \mathrm{L}^{-1}\right), 5 \mu \mathrm{L}$ of total DNA (200 ng $\mu \mathrm{L}^{-1}$ ), $0.5 \mu \mathrm{L}$ of 2 units per $\mu \mathrm{L}$ Taq DNA polymer- ase (Amersham-Pharmacia, USA), and $62.5 \mu \mathrm{L}$ of autoclaved double distilled water. Amplifications were performed with a cycling profile of $94{ }^{\circ} \mathrm{C}$ for $3 \mathrm{~min}$ followed by 25 cycles of $94^{\circ} \mathrm{C}$ for $1 \mathrm{~min}, 50^{\circ} \mathrm{C}$ for $1 \mathrm{~min}$ and $72{ }^{\circ} \mathrm{C}$ for $1 \mathrm{~min}$, followed by a final extension step of $72{ }^{\circ} \mathrm{C}$ for $10 \mathrm{~min}$. Amplification products were purified using ExoSap IT (Amersham-Pharmacia) and submitted to a cycle-sequencing reaction using the fluorescent-labeled dideoxy terminators supplied in the ABI PrismTM Dye Terminator Cycle Sequencing Ready Reaction kit (Applied Biosystems, USA). Sequencing reactions were performed in a $10 \mu \mathrm{L}$ reaction mixture containing $2 \mu \mathrm{L}$ of DNA, 0.5 ( $1 \mathrm{mM}$ ) of primer, $2 \mu \mathrm{L}$ of BigDye mix (Applied Biosystems, USA), $3 \mu \mathrm{L}$ of buffer $(200 \mathrm{mM}$ Tris plus $5 \mathrm{mM}$ $\mathrm{MgCl} 2$ ) and $2.5 \mu \mathrm{L}$ of autoclaved double distilled water, with a cycling profile of 25 cycles of $96^{\circ} \mathrm{C}$ for $30 \mathrm{~s}, 50{ }^{\circ} \mathrm{C}$ for $15 \mathrm{~s}$ and $60{ }^{\circ} \mathrm{C}$ for $1 \mathrm{~min}$. Unincorporated di-deoxynucleotides were removed by isopropanol washing according to the ABI chemistry manual instructions. The products were separated by electrophoresis ( $3 \mathrm{~h}$ at $3.000 \mathrm{~V}$ ) and the sequences collected using an ABI Prism 377 automated sequencer. The $12 \mathrm{~S}$ sequences generated in this study corresponding to bases 288 to 818 of the $C$. didactylus $12 \mathrm{~S}$ ribosomal RNA gene (Murphy et al., 2001) were aligned using the ClustalW program (Thompson et al., 1994) with default parameters. Minor modifications were made using the BIOEDIT sequence editor (Hall, 1999) and nucleotide saturation was assessed using the data analysis in molecular biology and evolution (DAMBE) program version 4.0.65 (Xia and Xie, 2001).

Phylogenetic reconstructions were performed using PAUP program version 4.0b10 (Swofford, 2003) and PHYML program version 2.4.4 (Guindon and Gascuel, 2003), with gaps treated as missing data in all analyses. The proper models for the likelihood phylogenetic analyses were selected with the Modeltest program version 3.07 (Posada and Crandall, 1998, 2001) using the Akaike's information criterion (AIC) according to Posada and Buckley (2004). In parsimony analyses the heuristic searches were done with 1000 random stepwise additions and subtree-pruning and the regrafting branch swapping algorithm (chosen arbitrarily). Node support for the parsimony and likelihood analyses was estimated using 1000 bootstrap (BS) pseudoreplicates (Felsenstein, 1985) and the Bremer decay (BD) index (Bremer, 1994). Monophyly tests were performed in PAUP using the nonparametric Templeton test for maximum parsimony (Templeton, 1983 ) or the Kishino-Hasegawa (KH) test (Kishino and Hasegawa, 1989) and the Shimodaira and Hasegawa (SH) test (Shimodaira and Hasegawa, 1999) likelihood tests for comparison of likelihood scores obtained in the maximum likelihood analyses.

We found that the mean transition transversion rate over all sequence pairs was 1.843 , ranging from a minimum of 1.0 to a maximum of 4.917 . The rate of transitions over 
Table 1 - Number, origin, and GenBank accession numbers of specimens used in our study.

\begin{tabular}{|c|c|c|c|}
\hline Scientific name (common name) & Code* & $12 S^{\dagger}$ & $16 \mathrm{~S}^{\dagger}$ \\
\hline \multicolumn{4}{|l|}{ Sloths } \\
\hline \multicolumn{4}{|l|}{ Bradypus } \\
\hline B. torquatus (maned sloth) & BratorBA80 & EF405918 & EF405904 \\
\hline B. torquatus & BratorBA77 & SA & EP405906 \\
\hline B. torquatus & BratorBA83 & SA & EF405905 \\
\hline B. tridactylus (three-toed sloth) & BratriPA18 & EF405917 & EF405902 \\
\hline B. tridactylus & BratriPA32 & SA & EF405903 \\
\hline B. variegatus (three-toed sloth) & BravarPA62 & EF405916 & EF405899 \\
\hline B. variegatus & BravarPA47 & SA & EF405901 \\
\hline B. variegatus & BravarPA57 & SA & EF405900 \\
\hline \multicolumn{4}{|l|}{ Choloepus } \\
\hline C. didactylus (two-toed sloth) & ChodidPA25 & EF405919 & EF405907 \\
\hline C. didactylus & ChodidPA75 & SA & EF405908 \\
\hline C. didactylus & ChodidPA61 & EF405920 & EF405909 \\
\hline C. didactyla (pigmy anteater) & CycdidPA11 & EF405910 & EF405887 \\
\hline C. didactyla & CycdidPA24 & SA & EF405888 \\
\hline C. didactyla & CycdidPB09 & EF405911 & EF405889 \\
\hline \multicolumn{4}{|l|}{ Mylodon } \\
\hline M. darwinii (mylodont, extinct) & MildarGB & Z48943 & Z48944 \\
\hline \multicolumn{4}{|l|}{ Anteaters } \\
\hline \multicolumn{4}{|l|}{ Cabassous } \\
\hline C. unicinctus (armadillo) & CabuniGB & AJ278151 & Z48940 \\
\hline \multicolumn{4}{|l|}{ Myrmecophaga } \\
\hline M. tridactyla (giant anteater) & MyrtriPI15 & EF405914 & EF405896 \\
\hline M. tridactyla & MyrtriPA76 & EF405915 & EF405897 \\
\hline M. tridactyla & MyrtriSP93 & SA & EF405898 \\
\hline \multicolumn{4}{|l|}{ Tamandua } \\
\hline T. tetradactyla (collared anteater) & TamtetPI04 & EF405911 & EF405890 \\
\hline T. tetradactyla & TamtetPA12 & SA & EF405894 \\
\hline T. tetradactyla & TamtetPA13 & SA & EF405892 \\
\hline T. tetradactyla & TamtetPA20 & SA & EF405893 \\
\hline T. tetradactyla & TamtetPA23 & SA & EF405891 \\
\hline T. tetradactyla & TamtetPA22 & EP405913 & EF405892 \\
\hline
\end{tabular}

*Source of the material used in this study. GB = GenBank. The following abbreviations indicate the Brazilian state: BA, Bahia; PA, Pará; PI, Piauí; and $\mathrm{SP}=$ São Paulo. ${ }^{\dagger}$ GenBank accession numbers. $\mathrm{SA}=$ same sequence as above.

transversions plotted against Kimura two parameter (K2P) distances (Kimura 1980) did not suggest saturation. Of the 539 aligned base pairs, excluding the gaps, 332 characters were constant and 207 were variable, with 182 characters being parsimony-informative. A branch and bound search recovered a single 363-step long most parsimonious tree with a consistency index (CI) of 0.75 and a re-scaled consistency index (RC) of 0.61 .

The bootstrap analyses showed the same topology for the majority rule consensus of 1,000 branch and bound search pseudoreplicates (Figure 1). Phylogenetic reconstruction showed sloths as a monophyletic group, strongly supported by bootstrapping $(\mathrm{BS}=99 \%)$ and Bremer decay
$(\mathrm{BD}=12)$, including two internal loosely supported clades, Bradypus $(\mathrm{BS}=70 \%, \mathrm{BD}=2)$ and Choloepus-Mylodon ( $\mathrm{BS}=79 \%, \mathrm{BD}=2)$. The Mylodon constrained to Bradypodidae or to Megalonychidae was not significant in the Templeton or Winning-sites test $(\mathrm{p}>0.55)$. However, when Mylodon was excluded from the analysis the support for the two clades rose to $91 \%$ for Bradypus and $100 \%$ for Choloepus (not shown in Figure 1). Among the anteaters, the relationship between myrmecophagids (Myrmecophaga) and tamandua (Tamandua) was strongly supported $(\mathrm{BS}=100 \%, \mathrm{BD}=16)$ but, surprisingly, the pigmy anteater (Cyclopes) appears as a sister group of sloths supported by a bootstrap value of $85 \%$ and Bremer decay index of 4 . 

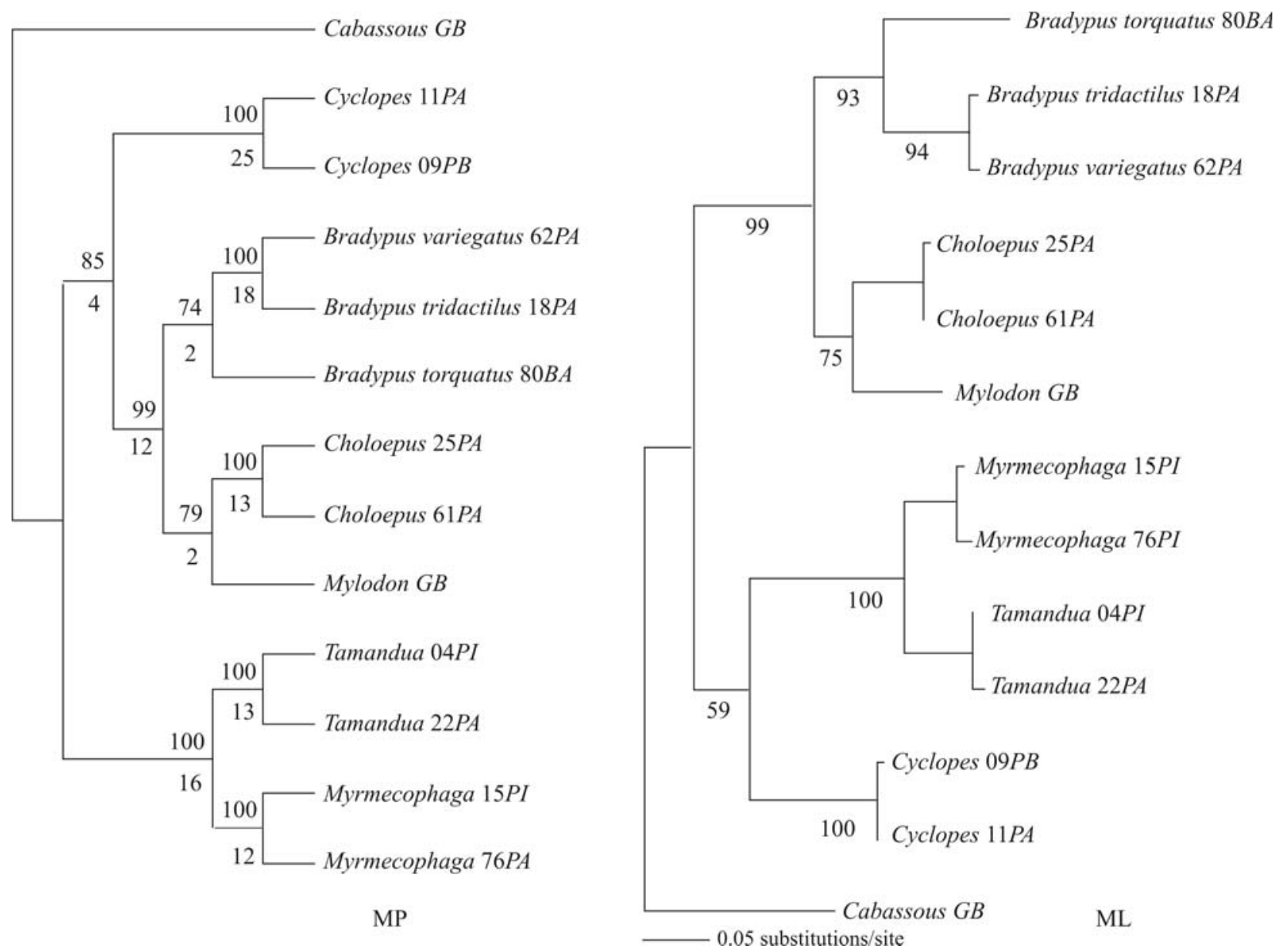

Figure 1 - Maximum parsimony (MP, left) and maximum likelihood (ML, right) bootstrap supports for 12S mtDNA in Pilosa. The numbers at the branches indicate Bremer decay (below) and MP bootstrap support based on 1,000 pseudoreplicates (above). For ML numbers at branches indicate bootstrap support based on 1,000 pseudoreplicates.

However, constraining the pigmy-anteater to the anteater clade, did not generate a significant drop $(\mathrm{p}=0.1655)$ in parsimony scores in the Templeton test, despite the suggestion (Hillis and Bull, 1993) that bootstraps percentages above $75 \%$ should be considered significant. Pol and Siddall (2001) have pointed out that in some cases differentially weighted parsimony can surpass equal weight parsimony, so we applied a progressive weighting schema varying from equal weight parsimony $(1: 1)$ to the maximum difference observed in the data, as well as a parsimony considering only transversions. For each weighting schema, a branch and bound search of 1000 pseudoreplicates was used to generate the bootstrap supports shown in Figure 2. Equal weight parsimony grouped the pigmyanteater with sloths with $85 \%$ bootstrap support and using weights of 2 and 5 a hard polytomy was obtained. Even when weights varying from 3 to 5 were used (or transversion parsimony) parsimony analysis did not place the pigmy-anteater into the Anteater clade with a reasonable support. The topology depicted by maximum likelihood showed the sloths as a monophyletic assemblage supported by significant bootstrap percentages (99\%). Figure 1 shows that all nodes are supported by bootstrap percentages above $90 \%$, except the Mylodon-Choloepus node ( $\mathrm{BS}=88 \%$ ) that despite the bootstrap support did not resist a monophyly test. As expected in the maximum likelihood analyses the unconstrained topology showed a likelihood of $-\operatorname{lnL}=2264.82967$ while the topology enforcing a Mylodon-Bradypus arrangement showed a likelihood of $-\operatorname{lnL}=2259.15255$, which did not correspond to a significant increase ( $p=0.167$ for the KH-test or 0.09 for the SH-test). However, the topology generated by maximum likelihood did not resolve the placement of pigmy anteater as the most basal taxa of the anteaters. All other nodes were supported by high bootstraps values (93\% to $100 \%)$. In general, our present data and mtDNA16S data from our previous work produced similar topologies, with the exception of the controversial placement of pigmy-anteater by parsimony analyses of mtDNA $12 \mathrm{~S}$.

The objective of this work was to contribute to knowledge on the relationships among extant sloths as well as the position of the extinct Mylodon in relation to the twoand three-toed extant sloths, including some taxa not previously investigated by $12 \mathrm{~S}$ mtDNA analysis. However, 


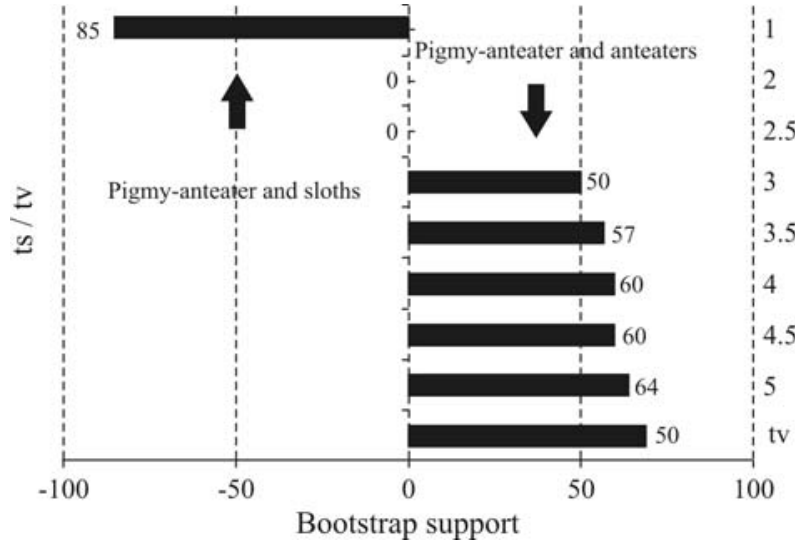

Figure 2 - Schematic representation of the effect on bootstrap support of down-weighting transitions. Numbers to the right indicate the transition (ts)/transversion (tv) ratio. The last " $t v$ " means that parsimony analysis was based only on transversions. Bootstrap support was estimated based on 1,000 branch and bound search pseudoreplicates.

some surprising results came up. One was the extraordinary distinctiveness of the Amazonian (B. tridactylus and $B$. variegates) and the Atlantic (B. torquatus) sloths, all of which belong to the Bradypodidae. As is well known in Brazil, B. tridactylus (the pale-throated three-toed sloth) and $B$. variegatus (the brown-throated three-toed sloth) inhabit the Amazon region, while B. torquatus (the maned three-toed sloth) is restricted to the Atlantic coastal forests of eastern Brazil. Based only on 16S rRNA analysis our previous estimates for the split between $B$. tridactylus and $B$. variegatus was at about $0.5 \mathrm{Ma} \mathrm{BP} \pm 0.4 \mathrm{Ma}$, suggesting that these species were probably a consequence of a recent evolutionary episode of sloth diversification. On the other hand, the split between the Amazonian sloths B. tridactylus and $B$. variegatus and the Atlantic forest sloth $B$. torquatus seems to have occurred much earlier in the Miocene period (23.03 Ma BP to 5.33 Ma BP). Despite the statistical uncertainty involved in these estimates, it is quite plausible that these estimates are much older than estimates obtained by some authors for other congeneric endemic species of these two biomes such as for curassows (Pereira and Baker, 2004), monkeys (Collins and Dubach, 2000; Cortés-Ortiz et al., 2003) and vesper mice (Salazar-Bravo et al., 2001). Furthermore, compared to the anteaters, the Atlantic/Amazonian sloth split is even older than the separation of the two anteaters Tamandua and Myrmecophaga. To maintain coherence between phylogeny and taxonomy, B. torquatus merits the status of a different genus (Scaeopus) as was previously proposed by Peters (1859) based on its distinctive morphological features (Paula Couto, 1979; Santos, 1977). However, the relationship of the extinct Mylodon to the extant sloths presented the same unresolved polytomy obtained in our previous work with $16 \mathrm{~S}$ mtDNA. However, the clade constituted by Mylodon, Choloepus and Bradypus is strongly supported, suggesting that they may comprise a monophyletic group. These results disagree with those of
Greenwood et al. (2001), who concluded that Mylodontidae (Mylodon darwinii) is associated with the Megalonychidae (Choloepus) while Megatheriidae (Nothrotheriops) is related to the Bradypodidae, based on very weak bootstrap support. Interestingly, recent cladistic analyses based on morphology (Gaudin, 2004), place Bradypus as the sister-taxon of all remaining sloths, and Choloepus as being closely related to the extinct Mylodontidae and Megatheriidae. Indeed, Gaudin (2004) emphasizes that the two extant families of sloths (Bradypodidae and Megalonychidae) represent diphyletic lineages and points out the similarities observed between the two taxa as one of the "most dramatic examples of convergent evolution known among mammals". Furthermore, Gaudin (2004) also suggests that the split between the two extant genera is an ancient event having occurred at about 40 MA. Delsuc et al. (2004) used molecular data and a relaxed molecular clock approach and advocated an age of around $21 \mathrm{Ma}$ for the split between the two extant sloth families. These two discrepant estimates cannot be easily reconciled. If Gaudin's (2004) interpretation is correct and the separation of extant sloths (Bradypus and Choloepus) occurred at $40 \mathrm{Ma}$ then the split between armadillos and Pilosa should be dramatically pushed back in time as well as the split between sloths and anteaters. These new estimates would have a profound impact on the beliefs about the origin and diversification of xenarthrans in the New World. However, Gaudin's (2004) phylogenetic tree shows the Mylodon x Choloepus clade, which also includes some megatheriids, supported by a moderate bootstrap value of $85 \%$ but no statistical support for the placement of Bradypus as the sister group of all sloths. In this case, the more appropriate representation of the relationship of Bradypus to the remaining edentata members is a polytomy. Additionally it is important to mention that no previous molecular study (Greenwood et al., 2001; Höss et al., 1996) has shown any significant support for the grouping of Mylodon with any of the extant sloths. These studies gave bootstrap values even smaller than the relaxed threshold of significance (75\%) advocated by (Hillis and Bull, 1993). Thus, considering the complexity of the evolutionary history of these creatures, the phylogenetic relationship between extant and extinct sloths is far from being unraveled.

Another interesting finding was the Cyclopes case. In our previous study using 16S rRNA (Barros et al., 2003), as well as from the results of other studies using more robust and less variable DNA data (Delsuc et al., 2001; Delsuc et al., 2002; Delsuc et al., 2004) or morphological analyses (Gaudin, 2004), Cyclopes unequivocally grouped with anteaters as the most basal mymercophagid genera. Surprisingly, in our present work with a fragment of $12 \mathrm{~S}$ rRNA parsimony analysis took Cyclopes out of the anteaters and placed it in closer relation to the sloths in a branch supported by a bootstrap value of $85 \%$ and a BD index of 4 . 
Maximum likelihood analyses generate a non-resolved topology showing the pigmy and the anteaters together but with non-significant statistical support. Despite the fact that a unique and partial gene generated this topology there are not many cases in the literature of a discrepancy of this magnitude. Interestingly, the $12 \mathrm{~S}$ rRNA did not show evidence of saturation (not shown). This peculiar branching pattern appears to be a very rare case of long-branch attraction (LBA), possibly caused not only by the fact that Cyclopes is basal in the Pilosa clade, or due to the small size of the 12S mtDNA fragment, but also due to the very ancient episode of Cyclopes radiation. Felsenstein (1978) first demonstrated LBA in parsimony or compatibility analysis based on a four-taxa case with unequal evolutionary rates and, since then, LBA has been a subject of great debate, with the use of the term having largely been diverse and vague. In his excellent review, Bergsten (2005) discusses various definitions of LBA and states that his usage is similar to, but slightly modified from, the definition of Sanderson et al. (2000) when they described LBA as "conditions under which bias in finite dataset analyses and/or statistical inconsistence arises due to a combination of long and short branches", and also from that given by Andersson and Swofford (2004) when they stated that LBA was "any situation in which similarity due to convergent or parallel changes produce an artifactual phylogenetic grouping of taxa due to an inherent bias in the estimation procedure". Hendy and Penny (1989) carried out a simulation using a five-taxon case and stated that it is not necessarily unequal rates, but unequal branch-lengths that can cause LBA. In addition, they affirmed that unequal branch lengths could be caused by either unequal rates or due to differential speciation rates or extinction rates along lineages, which seems to be the case for Cyclopes, a very ancient genus now represented by only a single species whose long evolutionary history was probably marked by dramatic episodes of speciation and/or extinction. Bergsten (2005) suggests a series of steps to characterize a case of LBA. We followed these steps, but bearing in mind that there was no discrepancy between previous morphological and molecular data. In other words, there is no doubt that Cyclopes is an anteater. So far, this short fragment of $12 \mathrm{~S}$ rRNA was the only one to generate this discrepancy. In summary, Bergsten's suggestions include (i) try different outgroups; (ii) test the effect of outgroup exclusion on the tree topology; (iii) include additional samples to break up the long branch. Following Bergsten's suggestions, we tested various members of the armadillo Cingulata clade as outgroup and the resulting topology was the same (not shown), with the new analysis, excluding the outgroup, showing a polytomic tree with three clades (sloths, medium-sized anteaters and pigmyanteaters) while reinserting the outgroup and excluding the pigmy-anteater did not change the general topology and the same polytomy was obtained. Breaking the pigmy longbranch was not possible because no other extant taxa exist in this branch. Thus, eliminating the long-branch attraction effect in this case was also not possible.

In conclusion, as previously suggested by our group (Barros et al. 2003) for an age based taxonomy to be coherent Cyclopes deserves the status of a family, resurrecting the proposal made by Paula Couto (1979) of creating the family Cyclopidae Hischfeld 1976 and adding this to Myrmecophagidae in the suborder Vermilingua. Additionally, our data also not only suggests that the pigmy-anteater is an extant case of the long-branch attraction effect for the small fragment of $12 \mathrm{~S}$ rRNA but also demonstrates the large genetic difference between the Amazonian (Bradypus) and Atlantic forest three-toed sloths (Scaeopus?) which inhabit these two remarkable Brazilian ecosystems which together are responsible for a considerable fraction of the biological diversity of the world.

\section{Acknowledgments}

We thank Marcia Chame of the Fundação Oswaldo Cruz for species identification, Dr. Niede Guidon for providing samples from the Parque Nacional da Serra da Capivara, Piauí, Brazil and Dr. João Morgante and Dr. Nádia de Moraes of the Universidade de São Paulo for providing samples of $B$. torquatus. This work was supported by grants (303426/2003-9, 479654/2003-4 and 476497/2001-9) from the Brazilian agencies Conselho Nacional de Desenvolvimento Científico e Tecnológico (CNPq), Coordenação de Apoio ao Pessoal de Ensino Superior (CAPES-PICD), Universidade Federal do Pará and Universidade Estadual do Maranhão.

\section{References}

Andersson FE and Swofford DL (2004) Should we be worried about long-branch attraction in real data sets? Investigations using metazoan 18S rDNA. Mol Phyl Evol 33:440-451.

Barros MC, Sampaio I and Schneider H (2003) Phylogenetic analysis of $16 \mathrm{~S}$ mitochondrial DNA data in sloths and anteaters. Genet Mol Biol 26:5-11.

Bergsten J (2005) A review of long-branch attraction. Cladistics 21:163-193.

Bremer K (1994) Branch support and tree stability. Cladistics 10:295-304.

Collins AC and Dubach JM (2000) Biogeographic and ecological forces responsible for speciation in Ateles. Int J Primatol 21:421-444.

Cortés-Ortiz L, Bermingham E, Rico C, Rodriguez-Luna E, Sampaio I and Ruiz-Garcia M (2003) Molecular systematics and biogeography of the neotropical monkey genus Alouatta. Mol Phylogenet Evol 26:64-81.

Delsuc F, Catzeflis FM, Stanhope MJ and Douzery EJP (2001) The evolution of armadillos, anteaters and sloths depicted by nuclear and mitochondrial phylogenies: Implications for the status of the enigmatic fossil Eurotamandua. Proc R Soc B: Biol Sci 268:1605-1615.

Delsuc F, Scally M, Madsen O, Stanhope MJ, de Jong WW, Catzeflis FM, Springer MS and Douzery EJP (2002) Molecular phylogeny of living xenarthrans and the impact of char- 
acter and taxon sampling on the placental tree rooting. Mol Biol Evol 19:1656-1671.

Delsuc F, Vizcaino S and Douzery E (2004) Influence of tertiary paleoenvironmental changes on the diversification of South American mammals: A relaxed molecular clock study within Xenarthrans. BMC Evol Biol 4:11.

Engelmann GF (1985) The phylogeny of the Xenarthra. In: Montgomery GG (ed) The Evolution and Ecology of Armadillos, Sloths and Vermilinguas. Smithsonian Institution, Washington DC, pp 51-63.

Felsenstein J (1978) Cases in which parsimony or compatibility methods will be positively misleading. Syst Zool 27:401410.

Felsenstein J (1985) Confidence limits on phylogenies: An approach using the bootstrap. Evolution 39:783-791.

Gaudin TJ (1995) The ear region of edentates and the phylogeny of the Tardigrada (Mammalia, Xenarthra). J Vertebr Paleontol 15:672-705.

Gaudin TJ (2004) Phylogenetic relationships among sloths (Mammalia, Xenarthra, Tardigrada): The craniodental evidence. Zool J Linn Soc 140:255-305.

Greenwood AD, Castresana J, Feldmaier-Fuchs G and Paabo S (2001) A molecular phylogeny of two extinct sloths. Mol Phylogenet Evol 18:94-103.

Guindon S and Gascuel O (2003) A simple, fast, and accurate algorithm to estimate large phylogenies by maximum likelihood. Syst Biol 52:696-704.

Hall TA (1999) Bioedit: A user-friendly biological sequence alignment editor and analysis program for Windows 95/98/Nt. Nucleic Acids Symp Ser 41:95-98.

Hendy MD and Penny D (1989) A framework for the quantitative study of evolutionary trees. Syst Zool 38:297-309.

Hillis DM and Bull JJ (1993) An empirical test of bootstrapping as a method for assessing confidence in phylogenetic analysis. Syst Biol 42:182-192.

Höss M, Dilling A, Currant A and Paabo S (1996) Molecular phylogeny of the extinct ground sloth Mylodon Darwinni. Proc Nat Acad Sci USA 93:181-185.

Kimura M (1980) A simple method of estimating evolutionary rate of base substitutions through comparative studies of nucleotide sequences. J Mol Evol 16:111-120.

Kishino H and Hasegawa M (1989) Evaluation of the maximum likelihood estimate of the evolutionary topologies from DNA sequence data, and the branching order in Hominoidea. J Mol Evol 29:170-179.

MacKenna M and Bell S (1997) Classification of Mammals Above the Species Level. Columbia University Press, New York, $631 \mathrm{pp}$.

Murphy WJ, Eizirik E, O'Brien SJ, Madsen O, Scally M, Douady CJ, Teeling E, Ryder OA, Stanhope MJ, de Jong WW, et al. (2001) Resolution of the early placental mammal radiation using Bayesian phylogenetics. Science 294:2348-2351.

Paterson B, Segall W, Turnbull WD and Gaudin TJ (1992) The ear region in xenarthrans (Edentata, Mammalia). Part II. Sloths, anteaters, palaeanodonts, and a miscellany. Field Geol New Series 24:1-79.

Paula Couto C (1979) Tratado de Paleomastozoologia. Acad Brasil Ciênc, Rio de Janeiro, 590 pp.

Pereira SL and Baker AJ (2004) A vicariant hypothesis for the speciation of curassows (Aves, Cracidae) based on mitochondrial DNA phylogeny. Auk 121:682-694.

Pol D and Siddall ME (2001) Biases in maximum likelihood and parsimony: A simulation approach to a 10 -taxon case. Cladistics 17:266-281.

Posada D and Buckley TR (2004) Model selection and model averaging in phylogenetics: Advantages of Akaike information criterion and Bayesian approaches over likelihood ratio tests. Syst Biol 53:793-808.

Posada D and Crandall KA (1998) Modeltest: Testing the model of DNA substitution. Bioinformatics 14:817-818.

Posada D and Crandall KA (2001) Selecting the best-fit model of nucleotide substitution. Syst Biol 50:580-601.

Salazar-Bravo K, Dragoo JW, Tinnin DS and Yates TL (2001) Phylogeny and evolution of the neotropical rodent genus Calomys: Inferences from mitochondrial DNA sequence data. Mol Phylogenet Evol 20:173-184.

Sambrook J, Fritsch EF and Maniatis T (1989) Molecular Cloning: A Laboratory Manual. Cold Spring Harbor Laboratory, New York.

Sanderson MJ, Wojciechowski MF, Hu JM, Khan TS and Brady SG (2000) Error, bias, and long-branch attraction in data for two chloroplast photosystem genes in seed plants. Mol Biol Evol 17:782-797.

Santos TMS (1977) Osteologia Craniana de Bradypus Linnaeus, 1758 e Reavaliação do Gênero Scaeopus Peters, 1865. Universidade Federal do Rio Grande do Sul, Porto Alegre, $178 \mathrm{pp}$.

Shimodaira H and Hasegawa M (1999) Multiple comparisons of log-likelihoods with applications to phylogenetic inference. Mol Biol Evol 16:1114-1116.

Swofford DL (2003) Paup* Phylogenetic Analysis Using Parsimony (*and Other Methods) v. 4. Sinauer Associates, Sunderland.

Templeton A (1983) Phylogenetic inference from restriction endonuclease cleavage site maps with particular reference to the evolution of humans and the apes. Evolution 37:221224.

Thompson JD, Higgins DG and Gibson TJ (1994) Clustal W: Improving the sensitivity of progressive multiple sequence alignment through sequence weighting, position-specific gap penalties and weight matrix choice. Nucleic Acids Res 22:4673-4680.

Xia X and Xie Z (2001) Dambe: Data Analysis in Molecular Biology and Evolution. J Hered 92:371-373.

Associate Editor: João S. Morgante

License information: This is an open-access article distributed under the terms of the Creative Commons Attribution License, which permits unrestricted use, distribution, and reproduction in any medium, provided the original work is properly cited. 